\title{
SOME CAUSES OF ERROR IN BLANK ANALYSES.
}

\section{By J. B. Mackintosh.*}

IN making chemical investigations, it is quite usual to run a blank analysis, in order to apply a correction to our results for the impurities contained in the reagents and for those entering into solution from the apparatus used. As a rule however, it seems to be entirely overlooked that the conditions of the actual analysis are often quite different from those obtaining in the case of the blank. For instance, let us assume the case of a limestone which has been dissolved in just sufficient hydrochloric acid to form a neutral solution of calcium chloride; at this stage our blank analysis will be a strongly acid solution. If we now add to both enough ammonia to neutralise the amount of hydrochloric acid previously employed, we will have in our actual analysis a strongly ammoniacal solution, while in our blank there will be a neutral solution of ammonium chloride, and similar results will take place on the addition of every reagent. In such a case our blank analysis will give us only approximately correct results, for though any impurities existing in the chemicals will be detected, yet the impurities which are dissolved from our beakers by the solutions, will be quite different in the case quoted, and the errors due to this last source may far exceed those due to impurities contained in the chemicals used.

The particular case of blank analysis to which I desire to call attention, serves to illustrate the serious error into which chemists may be led by faith in the infallibility of books of reference, whose statements, copied from one another, gain in authority through force of iteration, even though, as sometimes is the case, the original statement be erroneous.

Several years ago I had occasion to analyse a large number of samples of metallic copper and alloys of copper, and for the determination of arsenic I decided to use the method of distillation with ferric chloride and hydrochloric acid recommended in Crooke's Select Methods. $\uparrow$ In that work the statement is made that the ferric chloride employed may be freed from all traces of arsenic by one or two evaporations to dryness with hydrochloric acid, whereby the arsenic will all be volatilised as chloride. In following these directions I collected the distillates, thus making a blank analysis in all respects similar to the actual analyses performed later. When the distillates were tested for arsenic they were found to be perfectly free from that element, from whence the deduction was drawn that the reagents employed were pure. If the statement mentioned above was correct, then this deduction was justified by the facts observed. I noticed, however, that all the samples of copper I had, no matter of what quality, invariably caused the appearance of large quantities of arsenic in the distillates, and on repeating the experiment with the substitution of some charcoal for the copper, I likewise obtained arsenic in the distillate, and since the charcoal could not be suspected of being the source of the arsenic found, it was definitely traced to the ferric chloride, which by a blank analysis would have been pronounced pure. In this case the omission of the copper in the blank

* Journal of Analytical Chemistry.

$\dagger$ First Eidition, p. 266 ; Second Edition, p. 431. 
analysis was also the omission of a necessary reagent, without which or some substitute, the reaction would not take place. In fact, it is not until the arsenic is reduced to arsenious chloride that it will distil off, any arsenic in the higher form of oxidation not being volatile under these circumstances.

Here is a striking instance of the unreliability of blank analyses, unless all the circumstances be thoroughly comprehended and taken into account, and other instances of similar nature could readily be adduced. 